* Mestranda pela Universidade Estadual Paulista Júlio de Mesquita Filho - UNESP. Advogada. Pós-graduada em Direito Processual Civil e Argumentação Jurídica pela PUC-Minas, graduada pela Faculdade de Direito de Franca - SP

E-mail: mariana_menegaz@ hotmail.com

** Doutor em Direito pela Universidade Federal de Santa Catarina. Doutor em História pela Universidade Federal de Uberlândia - UFU. Mestre em Direito pela Universidade Federal de Santa Catarina. Professor dos programas de pós-graduação, mestrado em direito, da Universidade Federal de Uberlândia - UFU, e da Universidade Estadual Paulista Júlio de Mesquita Filho - UNESP

E-mail:walmott@gmail.com

\section{Os Direitos Humanos Sob a Perspectiva da Teoria Crítica e seus Reflexos no Acesso à Justiça}

\author{
Human Rights From The Perspective Of Critical \\ Theory And Some Reflections On Access To Justice
}

\section{Mariana Lima Menegaz* Alexandre Walmott Borges**}

Como citar: MENEGAZ, Mariana Lima; BORGES, Alexandre Walmott. Os direitos humanos sob a perspectiva da teoria crítica e seus reflexos no acesso à justiça. Revista do Direito Público, Londrina, v. 14, n. 2, p. 55-67, ago. 2019. DOI: 10.5433/24157-108104-1.2019v14n2p. 55. ISSN: 1980-511X

Resumo: $O$ presente trabalho possui como objetivo analisar o direito de acesso à justiça sob o âmbito da Teoria Crítica dos Direitos Humanos. Os Direitos Humanos estão dispostos na Constituição Federal de 1988 e um dos meios para efetivação deles é através do acesso à justiça, que está positivado no artigo $5^{\circ}, \mathrm{XXXV}$, daquele ordenamento. Este instituto encontra-se dentro do Título II, Dos Direitos e Garantias Fundamentais, evidenciando sua finalidade de amplo alcance para todos os cidadãos. Entretanto, ao verificar a realidade encontrada na sociedade atual, percebe-se que o acesso à justiça ainda não é amplo e igualitário aos indivíduos, constituindo um caráter universal, haja vista que há grande parte das pessoas que desconhecem seus direitos, ou, caso os conheça, não possuem condições de efetivá-los, apesar da disponibilização de alguns meios, como a atuação das Defensorias Públicas e o acesso à justiça gratuito. A problemática enfrentada quanto ao acesso à justiça é verificada ao analisar alguns fatores, como o econômico e o psicológico, mas também contempla sugestões para a efetivação deste direito.

Palavras-chave: Direitos humanos. Acesso à justiça. Teoria crítica. Constituição Federal. Universalidade.

Abstract: This study analyzes the right of access to justice under the scope of the Critical Theory of Human Rights. Brazil's Federal Constitution of 1988 established most fundamental rights and one of the most important means for guarenteeing them is with another right: access to justice, written in Article 5, XXXV, of that order. This institute belongs to the vast array of Fundamental Rights and Guarantees, which highlights its purpose and ample reach for every citizen. However, in verifying the reality found 
in today's society, this study perceives that access to justice - broad and equal to individuals, constituting a universalistic nature - is just a mere utopian idea, because many people are unaware of their rights or, if they are aware of them, are not in a position to take action, despite the availability of resouces, such as the Public Defender's Office and free access to justice. Most importantly, the problem facing access to justice is most noted when investigating some important factors, such as economic and psychological factors. Moreover, this paper also offers suggestions in order to implement this right realisticly and effectively.

Key-words: Human rights; Access to justice; Critical Theory; Federal Constitution; Universality. 


\section{INTRODUÇÃO}

O conceito de Direitos Humanos vem sendo consolidado, não havendo uma única definição. Isto ocorre em razão das modificações vivenciadas pelos indivíduos, que variam dependendo do contexto histórico, temporal e espacial em que cada sociedade está inserida.

Conforme disposto na Constituição Federal de 1988, em seu artigo $5^{\circ}$, XXXV, o acesso à justiça é um dos meios para que haja a garantia dos Direitos Humanos, que são inerentes a todo indivíduo.

Para isso, a Magna Carta indica o caráter universal e amplo da extensão do acesso à justiça, pressupondo que todos os cidadãos, sem exceção, têm o direito a procurar o Poder Judiciário sempre que for necessário, e, por consequência, tenham seus direitos totalmente assegurados e seus processos amplamente analisados, contemplando também outras garantias, como a celeridade (art. 5 ${ }^{\circ}$, LXXVIII, CF), o contraditório, a ampla defesa e o devido processo legal.

Observando o contexto histórico dos Direitos Humanos, percebe-se que existem influxos referentes à dominação dos povos, evidenciando as relações de poder e a violência manifestada nos Direitos Humanos desde antes da colonização europeia em território brasileiro.

Neste sentido, faz-se necessário o estudo dos Direitos Humanos sob a perspectiva da Teoria Crítica, analisando a trajetória histórica e as influências dos contextos vivenciados à época para a consolidação dos Direitos Humanos.

Esta análise é imprescindível para que seja possível entender quais são os obstáculos vivenciados no tocante ao efetivo acesso à justiça, suas causas e assim, traçar as possíveis considerações e sugestões sobre o tema.

Este trabalho pretende, portanto, abordar o acesso à justiça como direito fundamental e meio de garantia para a efetivação dos Direitos Humanos no contexto político e social, com o auxílio de alguns filósofos e juristas, conforme demonstrado no decorrer do artigo.

Para tanto, serão analisadas pesquisas bibliográficas sobre o acesso à justiça e sobre a Teoria Crítica dos Direitos Humanos, verificando também a positivação do tema no ordenamento jurídico brasileiro.

\section{DIREITOS HUMANOS E DIREITOS FUNDAMENTAIS}

Primeiramente, faz-se necessária a conceituação de Direitos Humanos e Direitos Fundamentais.

Os Direitos Humanos podem ser definidos como aqueles que visam proteger o indivíduo, possuindo um contexto histórico que provém da práxis cultural em que o indivíduo está inserido a um contexto, uma sociedade (AQUINO; NISTLER, 2016).

Segundo Bobbio (1992, p. 32), os Direitos Humanos buscam assegurar condições de dignidade mínima para o ser humano, surgindo e se aperfeiçoando gradativamente. Ademais, é uma maneira mais sucinta de contemplar os Direitos Fundamentais, sendo essenciais para a 
existência e para o desenvolvimento dos cidadãos (SPAREMBRGER; GUERRA, 2012, p. 1).

Os Direitos Fundamentais são os universais que valem para todos os indivíduos, independente de nacionalidade, gênero e outras características, como o direito à vida (BOBBIO, 1992, p. 78). Para Sarlet (2010, p. 31) tais direitos são definidos como:

Conjunto de direitos e liberdades institucionalmente reconhecidos e garantidos pelo direito positivo de determinado Estado, tratando-se, portanto, de direitos delimitados espacial e temporalmente, cuja denominação se deve ao seu caráter básico e fundamentador do sistema jurídico do Estado do Direito.

O próprio ordenamento jurídico brasileiro, na Constituição Federal de 1988, positiva os Direitos Humanos, ao indicar os Direitos Fundamentais, garantindo a dignidade humana, o direito à vida, e a liberdade, entre outros, assegurando, assim, a efetivação dos Direitos Humanos.

\section{ACESSO À JUSTIÇA}

O acesso à justiça é direito garantido na Constituição Federal de 1988, no artigo $5^{\circ}$, XXXV: “a lei não excluirá da apreciação do Poder Judiciário lesão ou ameaça de direito."

O legislador buscou abranger o maior número de situações para que qualquer indivíduo possa recorrer ao Judiciário, destacando, inclusive, casos que envolvam apenas a ameaça de um direito tutelado pelo ordenamento.

O direito de acesso à justiça não assegura apenas o acesso ao órgão do Poder Judiciário, mas sim a uma ordem jurídica justa, célere e efetiva, abrangendo tanto o âmbito judicial, quanto o extrajudicial. Assim, várias instituições podem atuar para que este direito seja efetivado.

$\mathrm{O}$ acesso à justiça está contido no Título II, Capítulo I, da Magna Carta, que disciplina os Direitos e Garantias Fundamentais e, mais especificamente, os Direitos e Deveres Individuais e Coletivos, evidenciando que a abrangência deve ocorrer de forma horizontal, alcançando todos os indivíduos da sociedade.

Segundo Cappelletti e Garth (1988, p. 12), o acesso à justiça é um direito básico para os indivíduos, porém, deve ser efetivo, assegurando um sistema igualitário na prática, e não apenas na teoria.

No âmbito internacional, a Declaração Universal dos Direitos Humanos, de 1948, em seu artigo $8^{\circ}$, também garante o acesso à justiça, estipulando que: "Toda pessoa tem direito a receber dos tribunais nacionais competentes remédio efetivo para os atos que violem os direitos fundamentais que lhe sejam reconhecidos pela constituição ou lei." (ORGANIZAÇÃO DAS NAÇÕES UNIDAS, 2009).

Ademais, a Convenção Americana de Direitos Humanos também assegura este direito em seus artigos 25 e 8 :

Artigo 8. Garantias judiciais. 1. Toda pessoa tem direito a ser ouvida, com as 
devidas garantias e dentro de um prazo razoável, por um juiz ou tribunal competente, independente e imparcial, estabelecido anteriormente por lei, na apuração de qualquer acusação penal formulada contra ela, ou para que se determinem seus direitos ou obrigações de natureza civil, trabalhista, fiscal ou de qualquer outra natureza. 2. Toda pessoa acusada de delito tem direito a que se presuma sua inocência enquanto não se comprove legalmente sua culpa. Durante o processo, toda pessoa tem direito, em plena igualdade, às seguintes garantias mínimas: a. direito do acusado de ser assistido gratuitamente por tradutor ou intérprete, se não compreender ou não falar o idioma do juízo ou tribunal; b. comunicação prévia e pormenorizada ao acusado da acusação formulada; c. concessão ao acusado do tempo e dos meios adequados para a preparação de sua defesa; d. direito do acusado de defender-se pessoalmente ou de ser assistido por um defensor de sua escolha e de comunicar-se, livremente e em particular, com seu defensor; e. direito irrenunciável de ser assistido por um defensor proporcionado pelo Estado, remunerado ou não, segundo a legislação interna, se o acusado não se defender ele próprio nem nomear defensor dentro do prazo estabelecido pela lei; f. direito da defesa de inquirir as testemunhas presentes no tribunal e de obter o comparecimento, como testemunhas ou peritos, de outras pessoas que possam lançar luz sobre os fatos; g. direito de não ser obrigado a depor contra si mesma, nem a declarar-se culpada; h. direito de recorrer da sentença para juiz ou tribunal superior. 3. A confissão do acusado só é válida se feita sem coação de nenhuma natureza. 4. $\mathrm{O}$ acusado absolvido por sentença passada em julgado não poderá ser submetido a novo processo pelos mesmos fatos 5.0 processo penal deve ser público, salvo no que for necessário para preservar os interesses da justiça (BRASIL, 1992).

Em razão do processo de colonização do território brasileiro, o direito sofreu várias influências do direito estrangeiro. Verifica-se que o direito europeu, principalmente, está enraizado no ordenamento jurídico brasileiro em todos os âmbitos, inclusive, no tocante aos Direitos Humanos.

Antes da Constituição Federal de 1988, o acesso à justiça era unicamente possível para aqueles indivíduos que possuíam renda para conseguirem quitar os valores decorrentes do processo, somado ainda com a importância paga ao seu advogado. Posteriormente este acesso foi ampliado, possibilitando que algumas pessoas pudessem recorrer ao órgão público para garantir os serviços jurídicos prestados e a isenção do pagamento de custas processuais.

A Magna Carta determina a aplicação da justiça gratuita (artigo $5^{\circ}, \mathrm{LXXIV}, \mathrm{CF} / 88$ ), conforme o texto legal que dispõe: "o Estado prestará assistência jurídica integral e gratuita aos que comprovarem insuficiência de recursos."

O acesso à justiça também foi ampliado no tocante ao direito do consumidor, com o Código de Defesa do Consumidor (Lei no 8.078/1990) (BRASIL, 1990), corroborado com a criação do PROCON (Programa de Proteção e Defesa do Consumidor), tendo em vista que o aumento do mercado de consumo criou uma nova demanda de direitos, sendo necessária que a resolução de tais litígios recebesse maior atenção.

Nesse sentido, é verificada a atuação das Defensorias Públicas, que tiveram início no ano de 
1897, no estado do Rio de Janeiro, e, atualmente, abrangem todo o território brasileiro ${ }^{1}$ (DALLEFI; FUNES, 2008). A Constituição Federal de 1988, no artigo 134, estabelece a Defensoria Pública como:

[...] instituição permanente, essencialà função jurisdicional do Estado, incumbindolhe, como expressão e instrumento do regime democrático, fundamentalmente, a orientação jurídica, a promoção dos direitos humanos e a defesa, em todos os graus, judicial e extrajudicial, dos direitos individuais e coletivos, de forma integral e gratuita, aos necessitados, na forma do inciso LXXIV do art. $5^{\circ}$ desta Constituição Federal (BRASIL, 1988).

Os Defensores Públicos possuem função imprescindível para a concretização do acesso à justiça. Entretanto, ainda que tenham sido instauradas diversas Defensorias Públicas no Brasil, e que o trabalho desenvolvido pelos (as) Defensores (as) seja excelente, as Defensorias Públicas são insuficientes para abrangerem toda a demanda.

Dados apontam que no estado do Ceará apenas $25 \%$ (vinte e cinco por cento) dos municípios possuem Defensorias Públicas. Em termos nacionais, pesquisa realizada pela Associação Nacional dos Defensores Públicos (ANADEP), comparando o número de Juízes e Magistrados, Promotores e Defensores Públicos, indicou que:

[...] Estado-Juiz possui 11.807 magistrados e desembargadores, 10.874 promotores e procuradores atuando no Estado-Acusação e apenas 5.935 defensores públicos para garantir o acesso à Justiça, o Estado-Defesa, para a maioria da população. Segundo o estudo, seriam necessários no país mais seis mil profissionais, mais que o dobro dos que existem hoje, para atender às necessidades das parcelas mais vulneráveis da sociedade (ANADEP, 2018).

Desse modo, é possível perceber a discrepância entre o total de Defensores Públicos, comparado com os Juízes e os Promotores, além de confirmar que o número de Defensores Públicos é inferior ao necessário para atender a parcela mais vulnerável da sociedade.

A problemática envolvendo o acesso à justiça é vasta, abrangendo desde a impossibilidade de acesso universal ao órgão judiciário estatal, até a falta de acesso a uma ordem jurídica justa. (WATANABE, 1988).

\subsection{FATORES QUE INTERFEREM NO EFETIVO ACESSO À JUSTIÇA}

Conforme destacado anteriormente, existem vários fatores que interferem negativamente no efetivo acesso à justiça, entre eles, alguns citados a seguir (TORRES, 2002).

Primeiramente, destaca-se o aspecto econômico, evidenciado pela grande desigualdade econômica vivenciada pela sociedade brasileira, em que as minorias são esquecidas completamente

\footnotetext{
1 A título de informação, a Constituição de 1934, no artigo 113, n 32 afirmava que: “A União e os Estados concederão aos necessitados assistência jurídica, criando, para esse efeito, órgãos especiais e assegurando a isenção de emolumentos, custas, taxas e selos".
} 
e as diferenças estão cada vez mais acentuadas. Auxilia este argumento os gastos processuais com advogados, custas processuais, pagamento de perícias, entre outras despesas relacionadas ao processo judicial que tramita no Judiciário.

Ainda no tocante às questões econômicas, é necessário considerar o aspecto do indivíduo, porém, também do Poder Público.

Conforme já indicado, o número de Defensorias Públicas consolidadas no território brasileiro não é suficiente para atender a toda população. Pesquisas realizadas no IV Diagnóstico da Defensoria Pública no Brasil, no ano de 2015, indicam que, tanto para os Defensores Públicos estaduais, como também para os federais, a principal medida para melhorar o acesso à justiça e o sistema jurídico é, em primeiro lugar, a "ampliação e o fortalecimento da atuação da Defensoria Pública.” (GONÇALVES; BRITO; FILGUEIRA, 2015, p. 129).

Ademais, afirmam que "emuma perspectiva futura, demonstramanecessidade de manutenção da busca pela ampliação dessa instituição, assim como pelo fortalecimento e equiparação perante aos demais órgãos do Sistema de Justiça." (GONÇALVES; BRITO; FILGUEIRA, 2015, p. 129), ressaltando que ainda é necessário mais investimento e ampliação das Defensorias Públicas.

Outro fator importante é o sociocultural, que está diretamente relacionado com a falta de conhecimento do cidadão sobre os seus direitos e sobre as maneiras corretas para tutelá-los.

Várias são as pessoas que desconhecem possuir tal direito e, em outros casos, identificam o direito, porém, não sabem qual a forma de reivindica-lo ou para quem devem recorrer a fim de obter o auxílio jurídico correto.

Nesse sentido, verifica-se que a criação de políticas públicas é uma solução para a ampliação do conhecimento para toda a população acerca dos seus direitos e deveres como cidadão, o que auxilia para que cada indivíduo tenha a consciência de quando é realmente necessário procurar o auxílio do Poder Judiciário, ou quando a própria comunicação com a outra parte é o meio mais adequado para alcançar a solução ao litígio.

Destaca-se que o Ministério da Educação homologou parecer do Conselho Nacional da Educação, conforme Portaria $n^{\circ}$ 1.351, publicada no D.O.U. de 17/12/2018, Seção 1, pág. 34 (BRASIL, 2018), que determina novas diretrizes para as instituições de ensino jurídico no Brasil, passando a ser obrigatória a disciplina de Formas Consensuais de Solução de Conflitos, abrangendo a mediação, a conciliação e a arbitragem.

Desse modo, os alunos de direito são formados para atuar com os mecanismos consensuais, e não apenas com o tradicional processo judicial.

Ademais, a Portaria também indica a obrigatoriedade de que o estudante de direito realize estágio nos Núcleos de Prática Jurídica das instituições, com o objetivo de capacitá-lo para a advocacia, além de abordar todas as formas de solução de controvérsias.

$\mathrm{O}$ fator psicológico também possui grande relevância no tocante ao acesso à justiça. $\mathrm{O}$ estigma trazido pelas denominações de "réu" ou de "autor" em algum processo judicial comportam uma carga elevada, além dos temores envolvendo represálias por ser parte de algum processo e também pelas decepções decorrentes do processo judicial. 
Além disso, a cultura do litígio está presente no cotidiano da maioria dos brasileiros, que veem no Poder Judiciário o único local possível para dirimir seus conflitos, ainda que estes sejam simples e de fácil solução entre as próprias partes.

Ressalta-se que também é considerada função do Poder Judiciário informar aos indivíduos que em determinadas circunstâncias é indicado que eles mesmos solucionem suas controvérsias, através da estimulação do diálogo e do empoderamento das partes.

Por fim, é importante ressaltar que estas questões contribuem para que o acesso à justiça exista, abrangendo todos os indivíduos da sociedade.

\section{A TEORIA CRÍTICA DOS DIREITOS HUMANOS E O ACESSO À JUSTIÇA}

O direito fundamental de acesso à justiça ainda não é amplamente efetivo, conforme a Constituição Federal de 1988 institui.

Portanto, para entender realmente o que originou os Direitos Humanos, faz-se necessário realizar a análise por outra perspectiva, diferente da tradicional, através de um novo olhar mais crítico do que o comumente utilizado.

Desse modo, passa-se a observar uma "reinvenção dos direitos humanos" (FLORES, 2009, p. 232), vislumbrada através da Teoria Crítica dos Direitos Humanos.

Atualmente, é imprescindível verificar os Direitos Humanos por essa outra perspectiva, para que assim ocorra uma reavaliação e readequação, rompendo com uma "legitimação formalista e abstrata" (FLORES, 2009, p. 232; MAÇALAI; STRUCKER, 2016; RIBEIRO; SPAREMBERGER, 2014, p. 10).

A grande motivação para a perspectiva da Teoria Crítica é a insatisfação com a observância restrita do tema na sociedade contemporânea. Assim, almeja-se uma verificação mais ampla, compreendendo as relações sociais em sua totalidade, bem como as lutas políticas e sociais que foram vislumbradas no desenvolvimento dos Direitos Humanos. Também objetiva-se, evidenciar as supressões de direitos para parte da população (PERIUS, 2013, p. 49).

Nesse sentido, Flores (2009, p. 232) afirma que o mercado possui grande influência na interpretação dos direitos, além do liberalismo econômico, que atuou diretamente no intrínseco das pessoas e na forma delas agirem em sociedade.

Com o advento da Revolução Francesa, aliada aos ideais Iluministas da Independência dos Estados Unidos, inicia-se uma nova etapa ideológica no ocidente mundial, caracterizando a transição para a Era Moderna, influenciando todas as sociedades, não apenas culturalmente, mas também juridicamente, principalmente com a expansão do capitalismo.

Assim, verifica-se a construção dos Direitos Humanos no momento histórico da difusão global do sistema econômico capitalista, evidenciando a ascensão da burguesia e a decorrente queda da nobreza e do clero. Nesse sentido, os Direitos Humanos são pensados e determinados em uma mentalidade capitalista, restando evidente seus traços na própria definição desses direitos.

Destaca-se, portanto, segundo esta Teoria, que os Direitos Humanos podem ser considerados 
como direitos que são pautados sob o âmbito da universalidade e estatização, porém são apenas reflexos dos efeitos da colonização europeia e da notória imposição decorrente dos excessos de poder.

Percebe-se uma nítida assimetria e desigualdade estabelecidas internamente nas sociedades. A discriminação, a marginalização e a inferioridade de parcela dos indivíduos evidenciam a divisão social, etária, racial, cultural, territorial e de classe, que foi estabelecida pelo modo de produção capitalista moderno-patriarcal.

Em um primeiro aspecto, faz-se necessário destacar os Direitos Humanos e a perspectiva crítica no tocante à universalidade existente. A princípio, esses direitos são transmitidos para a sociedade como igualitários, pregando a inclusão de todos os cidadãos, entretanto, não abrangem a igualdade e efetividade em todos os âmbitos populacionais.

Corrobora com esse entendimento, o argumento de David Sanchez Rubio (2015, p. 184), conforme verificado a seguir:

[...] Es decir, la universalidad de los derechos humanos se construye sobre discursos que defienden inclusiones en abstracto de todas las personas, pero sobre la base trágica y recelosa de exclusiones concretas, individuales y colectivas, marcadas por la nacionalidad, el racismo, el androcentrismo, el clasismo, la riqueza suntuaria como fin en sí mismo o el concepto de ciudadanía que se multiplican y acentúan contra quienes no poseen una nacionalidad de un estado considerado constitucional y de derecho.

Tal entendimento evidencia que os direitos são construídos em bases de concreta exclusão. Resta assim a afirmação de que esses direitos não são frutos de um processo construído através de uma luta universal a favor da real dignidade, com princípios, normas e valores, mas apenas a criação de uma única cultura que é a ocidental moderna e capitalista (RUBIO, 2015, p. 185).

Portanto, quanto ao aspecto universalista dos direitos humanos, conclui-se que não vislumbram os oprimidos e os menos favorecidos, como, por exemplo, aquelas pessoas com baixa renda econômica que não possuem acesso à saúde, segurança, medicamentos, e ainda, o amparo no judiciário, pois, por mais que existam Defensorias Públicas por todo o território brasileiro, estas não são suficientes para atender toda a demanda, ou mesmo a população desconhece suas existências e, ainda pior, os seus direitos. Conclui-se, assim, que o universalismo dos Direitos Humanos ainda não foi efetivado (ROMAGUERA, 2014, p. 12).

Nesse sentido, Flores (2009, p. 34) afirma que os Direitos Humanos são o "resultado sempre provisório das lutas que os seres humanos colocam em prática para ter acesso aos bens necessários para a vida".

Pesquisas realizadas analisando o período entre os anos de 2004 e 2009 (Panorama de Acesso à Justiça no Brasil) indicam que um grande grupo de pessoas não possui acesso à justiça (CONSELHO NACIONAL DE JUSTIÇA, 2001, p. 29).

Segundo os resultados, 257.379 dos respondestes da pesquisa afirmaram que não recorriam ao Judiciário, pois não sabiam que poderiam ter acesso a ele, o que indica que é necessário maior 
divulgação sobre a amplitude dos direitos assegurados aos indivíduos, assim como quais os mecanismos para alcançá-los.

Aprofundando a pesquisa, após analisarem o perfil socioeconômico daqueles que responderam que desconheciam a possibilidade e o direito de acesso ao Judiciário, verificaram que as pessoas com menor renda mensal econômica faziam parte deste grupo. Assim também foi o resultado daqueles que afirmaram sobre a impossibilidade de acesso, pois o "processo custaria muito caro" e "era muito longe" (CONSELHO NACIONAL DE JUSTIÇA, 2001, p. 30).

Como alternativas para solucionar tais questões, a própria pesquisa aponta alguns fatores, como:

A necessidade de intensificar as políticas de interiorização das serventias judiciais, o que certamente poderá ampliar o nível de conhecimento das pessoas que vivem nos municípios sem serventias judiciais suficientes, ou com número insuficiente. Tais evidências permitem afirmar que o desconhecimento é uma barreira de acesso à justiça que assola em maior monta aqueles com menor poder econômico. Em linhas mais gerais, a cadeia causal aqui descoberta expõe que níveis básicos de conhecimento jurídico direcionados à grande massa da população deveriam estar entre as prioridades da política judiciária Nacional (CONSELHO NACIONAL DE JUSTIÇA, 2001, p. 32).

Portanto, as questões relacionadas ao acesso à justiça devem ser repensadas, objetivando sempre a efetivação de forma universal e horizontal.

Ademais, Douzinas aponta outra questão a fim de efetivar os Direitos Humanos na sociedade atual:

[...] se os direitos humanos se tornaram o mito realizado das sociedades pósmodernas, a sua história exige que reavaliemos suas promessas longe da arrogância, autossatisfeita dos Estados e dos apologistas liberais; e tentemos descobrir estratégias políticas e princípios morais que não dependam exclusivamente da universalidade da lei, da arqueologia do meio ou do imperialismo da razão (DOUZINAS, 2007, p. 26).

Apenas através da Teoria Crítica dos Direitos Humanos é que se torna capaz o entendimento acerca das razões para que estes direitos não contemplem e não se estendam a todos os indivíduos da sociedade.

Desse modo, é necessário conceder especial atenção para a realidade concreta vivenciada na sociedade brasileira, minimizando as questões que impedem que o acesso à justiça seja universal, fomentando práticas educativas e sociais para que os Direitos Humanos efetivamente alcance todos.

\section{CONCLUSÃO}


A partir da pesquisa realizada, é possível concluir que várias são as questões que influenciam diretamente na concretização do acesso à justiça.

O direito do acesso à justiça, disposto na Constituição Federal de 1988, vem sendo ampliado nas últimas décadas, ainda que não em todos os aspectos, mas em algumas vertentes. Destaca-se a instituição dos Juizados Especiais, das Defensorias Públicas, da possibilidade de justiça gratuita, e, da instituição do PROCON (Programa de Proteção e Defesa do Consumidor), e do Código de Defesa do Consumidor (Lei no 8.078/90).

Entretanto, ainda é possível e necessário ampliar de forma universal o acesso à justiça. Para isto, novas políticas públicas são importantes para que a sociedade tenha conhecimento dos seus direitos e também para que saiba os locais e as pessoas adequadas para satisfazê-los. Ademais, é importante ressaltar a disseminação dos mecanismos consensuais, como a mediação, a conciliação e a arbitragem, ainda na graduação dos estudantes de direito, para que os profissionais tenham conhecimento teórico e prático de todas as formas de solução de controvérsias, refletindo também no aumento do acesso à justiça.

Ademais, a exclusão e a opressão devem ser combatidas diariamente, não aceitando a naturalização da injustiça cotidiana. Portanto, os Direitos Humanos devem ser analisados sob a perspectiva da Teoria Crítica, haja vista que apenas entendendo o passado, as influências e os desejos reais e intrínsecos dentro de cada sociedade que auxiliou na construção daquele ordenamento jurídico, é que novas realidades poderão ser criadas, sendo elas mais plurais, dialogando com as minorias, garantindo assim o acesso à justiça completo, efetivo, universal e horizontal.

\section{REFERÊNCIAS}

ANADEP - ASSOCIAÇÃO NACIONAL DAS DEFENSORAS E DEFENSORES PÚBLICOS. Só um em cada quatro municípios cearenses tem defensor público. O Povo Online, Ceará, 8 nov. 2018.

AQUINO, Sérgio Ricardo Fernandes de; NISTLER, Regiane. Direitos humanos e direitos fundamentais: proximidades e diferenças. 2016. Disponível em: https://emporiododireito.com. $\mathrm{br} /$ leitura/direitos-humanos-e-direitos-fundamentais-proximidades-e-diferencas. Acesso em: 18 jun. 2017.

BOBBIO, Norberto. A era dos direitos. Tradução de Carlos Nelson Coutinho. Rio de Janeiro: Campus, 1992.

BRASIL. [Constituição Federal (1934)]. Constituição da República dos Estados Unidos do Brasil. (De 16 de julho de 1934). Brasília: Presidência da República, 1934. Disponível em: http://www.planalto.gov.br/ccivil_03/constituicao/constituicao34.htm. Acesso em: 20 jun. 2017.

BRASIL. [Constituição Federal (1988)]. Constituição da República Federativa do Brasil. Brasília: Presidência da República, 1988. Disponível em: http://www.planalto.gov.br/ccivil_03/ constituicao/constituicaocompilado.htm. Acesso em: 20 jun. 2017.

BRASIL. Decreto n 678 de 6 de novembro de 1992. Promulga a Convenção Americana sobre 
Direitos Humanos (Pacto de São José da Costa Rica), de 22 de novembro de 1969. Diário Oficial da União, Brasília, 6 nov. 1992. Disponível em: http://www.planalto.gov.br/ccivil_03/ decreto/d0678.htm. Acesso em: 21 jun. 2017.

BRASIL. Lei no 8.078, de 11 de setembro de 1990. Dispõe sobre a proteção do consumidor e dá outras providências. Diário Oficial da União, Brasília, 11 set. 1990. Disponível em: http://www. planalto.gov.br/ccivil_03/Leis/L8078.htm. Acesso em: 08 fev. 2019.

BRASIL. Ministério da Educação. Portaria n ${ }^{\circ}$ 1.351, de 04 de outubro de 2018. Diário Oficial da União, Brasília. DF, 17 dez. 2018. Disponível em: http://portal.mec.gov.br/ index.php?option=com_docman\&view=download\&alias=100131-pces635-18\&category_ slug=outubro-2018-pdf-1\&Itemid=30192. Acesso em: 07 fev. 2019.

CAPPELLETTI, Mauro; GARTH, Bryant. Acesso à justiça. Tradução de Ellen Gracie Northfleet. Porto Alegre: Sérgio Antonio Fabris, 1988.

CONSELHO NACIONAL DE JUSTIÇA. Panorama de acesso à justiça no Brasil. jul. 2001. Disponível em: http://www.cnj.jus.br/files/conteudo/ arquivo/2016/03/69f08fa6be2b411e6566b84bdc1d4b5a.pdf. Acesso em: 20 jun. 2017.

DALLEFI, Nayara Maria Silvério da Costa; FUNES, Gilmara Pesquero Fernandes Mohr. A Defensoria Pública. 2008. Disponível em: http://intertemas.unitoledo.br/revista/index.php/ ETIC/article/viewFile/1842/1748. Acesso em: 22 jun. 2017.

DOUZINAS, Costas. O fim dos direitos humanos. São Leopoldo: Unisinos, 2007.

FLORES, Joaquín Herrera. A reinvenção dos direitos humanos. Tradução de Carlos Roberto Diogo Garcia, Antônio Henrique Graciano Suxberger e Jefferson aparecido Dias. Florianópolis: Fundação Boiteux, 2009.

GONÇALVES, Gabriella Vieira Oliveira; BRITO, Lany Cristina Silva; FILGUEIRA, Yasmin von Glehn Santos. IV diagnóstico da Defensoria Pública no Brasil. Brasília, 2015. 138 p. Disponível em: https://www.anadep.org.br/wtksite/downloads/iv-diagnostico-da-defensoriapublica-no-brasil.pdf. Acesso em: 8 fev. 2019.

MAÇALAI, Gabriel; STRUCKER, Bianca. Direitos humanos pensados a partir da periferia: resenha da obra fundamentação dos direitos humanos desde a filosofia da libertação, de Alejandro Rosillo Martinez. Pensar a Prática, Goiânia, v. 19, n. 3, 2016. Disponível em: https:// www.revistas.ufg.br/fef/article/view/41394. Acesso em: 18 jun. 2017.

ORGANIZAÇÃO DAS NAÇÕES UNIDAS. Declaração Universal dos Direitos Humanos. jan. 2009. Disponível em: https://nacoesunidas.org/wp-content/uploads/2018/10/DUDH.pdf. Acesso em: 20 jun. 2017.

PERIUS, Odeide. Os direitos humanos na perspectiva da teoria crítica. Revista Filosofazer, Passo Fundo, n. 43, jul/dez. 2013.

RIBEIRO, Bernard Constantino; SPAREMBERGER, Raquel Fabiana Lopes. Os direitos humanos e as perspectivas decoloniais: a condição do sujeito subalterno no Brasil. Revista Amicus Curiae, Criciúma, v.11, 2014. Disponível em: http://periodicos.unesc.net/amicus/article/ view/1709. Acesso em 20 jun. 2017. 
ROMAGUERA, Daniel Carneiro Leão. A concepção ocidental de direitos humanos e seus paradoxos: por uma crítica à sujeição humanista na contemporaneidade. 2014. Dissertação (Mestrado em Direito) - Universidade Católica de Pernambuco, Recife, 2014.

RUBIO, David Sanchéz. Derechos humanos, no colonialid y otras luchas por la dignidad: uma mirada parcial y situada. Campo Jurídico, Barreiras-BA, v. 3, n. 1, p. 181-213, maio 2015.

SARLET, Ingo Wolfgang. A eficácia dos direitos fundamentais. 10. ed. Porto Alegre: Livraria do Advogado, 2010.

TORRES, Ana Flavia Melo. Acesso à Justiça. Âmbito Jurídico, Rio Grande, v. 3, n. 10, ago., 2002. Disponível em: http://www.ambito-juridico.com.br/site/index.php?n_link=revista_artigos_ leitura\&artigo_id=4592. Acesso em: 10 jun. 2017.

WATANABE, Kazuo. Acesso à justiça e sociedade moderna. In: GRINOVER, Ada Pellegrini; DINAMARCO, Cândido Rangel; WATANABE, Kazuo (org.). Participação e processo. São Paulo: RT, 1988, p. 128-135.

Como citar: MENEGAZ, Mariana Lima; BORGES, Alexandre Walmott. Os direitos humanos sob a perspectiva da teoria crítica e seus reflexos no acesso à justiça. Revista do Direito Público, Londrina, v. 14, n. 2, p. 55-67, ago. 2019. DOI: 10.5433/24157-108104-1.2019v14n2p. 55. ISSN: 1980-511X

Recebido em: 14/08/2017.

Aprovado em: 08/07/2019. 